Journal of Advanced Research in Fluid Mechanics and Thermal Sciences

Journal homepage: www.akademiabaru.com/arfmts.html ISSN: 2289-7879

\title{
Optimization of NPK Medium with the Addition of Mung Bean Sprout Extract for Biomass and Lipid Production of Stanieria HS-48 as a Potential Biofuel
}

\author{
Ni Wayan Kristina Eka Yanti ${ }^{1}$, Aditya Toriq Rochmanto ${ }^{1}$, Sri Handayani ${ }^{2}$, Nasruddin $^{3}$, Nining \\ Betawati Prihantini ${ }^{1, *}$

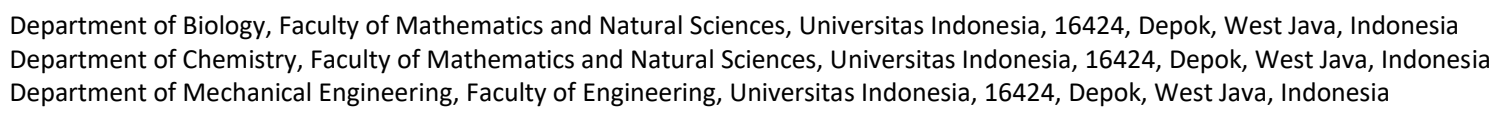

\section{Article history:}

Received 12 November 2020

Received in revised form 10 March 2021

Accepted 15 March 2021

Available online 8 April 2021

\begin{abstract}
Stanieria strain HS-48 from Ciater hot spring, Indonesia contains lipid content in the form of fatty acids that can be used as a raw material for biodiesel. Optimization of the growth medium was used to produce high contents of microalgal lipids. The growth medium in this study utilized NPK medium with the addition of variations in the concentration of mung bean sprout extract $2 \%$ and $4 \%$. This study aimed to determine the best concentration of mung bean sprout extract in NPK medium for the highest biomass and lipid production of Stanieria HS-48. The experiments were conducted in airlift photobioreactors (APBR) for 19 days. The highest total cell density of Stanieria HS-48 in NPK medium with the addition of variations in the concentration of mung bean sprout extract $2 \%$ and $4 \%$ were $6.165 \times 10^{6}$ and $4.702 \times 10^{6}$ cell $/ \mathrm{ml}$. The lipid content of the biomass from Stanieria HS- 48 on NPK medium with the addition of mung bean sprout extract $2 \%$ and $4 \%$ were $62.9 \%$ and $44.8 \%$. The study showed that the NPK medium with the addition of the concentration of mung bean sprout extract $2 \%$ was a good growth medium for increasing biomass and lipid of Stanieria HS-48.
\end{abstract}

\section{Keywords}

mung bean sprout extract; biofuel; lipid; NPK fertilizer; Stanieria HS-48

\section{Introduction}

Microalgae has the potential to be used as renewable energy resources [1]. Microalgae have more efficient $\mathrm{CO}_{2}$ uptake compared to terrestrial plants about 10-50 times higher. The $\mathrm{CO}_{2} \mathrm{can}$ be used or stored as feedstock to produce biomass in the photosynthesis pathway. Microalgal biomass contains lipids that can be processed into many potential energy products such as biodiesel, syngas, hydrogen, or methane. Dunaliella salina is one of a few microalgae that can be cultivated to produce the lipid. D. salina can produce total lipids with a percentage of $40.65 \%$ from $551 \mathrm{mg}$ of biomass [2]. One of the microalgae that have the potential to produce biofuel is cyanobacteria. Stanieria HS-48 is one of the indigenous cyanobacteria that has the potential to produce lipid, due to the composition

\footnotetext{
* Corresponding author.

E-mail address: nining.prihantini@gmail.com / nining@sci.ui.ac.id
}

https://doi.org/10.37934/arfmts.82.1.7784 
of fatty acid in Stanieria HS-48 such as polyunsaturated fatty acid with a percentage of $32.15 \%$, monounsaturated fatty acid with a percentage of $53.24 \%$, and hydroxy-substituted fatty acid with a percentage of $14.61 \%$ [3].

To produce microalgae biomass for biofuel production on an industrial scale, optimization on the growth medium is needed to cost efficiency. The NPK medium is the most used for the economical medium of microalgae. However, the nutrient in the NPK medium was not optimum for the growth of Stanieria HS-48, so it needed natural substances such as mung bean sprout extract because it contains macronutrient, micronutrient, and vitamin. The research of mung bean sprout extract for growth media had been done by Prihantini et al., [4]. Based on the results shown the optimum concentration of mung bean sprout extract for the growth of Scenedesmus in ranging 2-4\% [4]. The research about the addition of variations in the concentration of mung bean sprout extract in NPK medium for Stanieria HS-48 for an alternative medium has not been done, therefore it is needed. NPK medium with the addition of variations in the concentration of mung bean sprout extracts $2 \%$ and $4 \%$. So, the study aimed to determine the effect of mung bean sprout extract in NPK medium for biomass and lipid production of Stanieria HS-48. The addition of mung bean sprout extract with the right concentration was expected to increase the biomass and lipid production of Stanieria HS-48 as a potential biofuel.

\section{Methodology}

\subsection{Microorganism and Culture Medium}

Stanieria HS-48 was isolated from Ciater hot spring, as indigenous cyanobacteria [5]. The strain was enriched in BBM as a basal growth medium and incubation at $30^{\circ} \mathrm{C}$. The culture medium was BBM as control and NPK with the addition of the mung bean sprout extract as a treatment. The concentration of mung bean sprout extract that used was $2 \%$ and $4 \%$. The NPK medium with the addition of mung bean sprout extract $2 \%$ and $4 \%$ were made by mixing $350 \mathrm{mg}$ of NPK 12:12:17 fertilizer and $20 \mathrm{~mL}$ and $40 \mathrm{~mL}$ of mung bean sprout into distilled water. The components homogenized using a magnetic stirrer at a speed of $1200 \mathrm{rpm}$ for 15 minutes and sterilized by autoclave.

\subsection{Extraction of Total Lipid}

Lipid extraction was done with the modification of Bligh \& Dyer methods (1959). The biomass of Stanieria HS-48 centrifugated at a speed of 6,000 rpm for 15 minutes. After that, a mixture of chloroform and methanol in proportions 1:2 was added to the biomass, then the mixture was sonicated for 30 minutes. A mixture of distilled water and chloroform in proportions 1:1 was added then the mixture was sonicated again for 30 minutes. After that, the mixture was centrifugated with $4,000 \mathrm{rpm}$ for $15-20$ minutes. The supernatant was collected then transferred to a separatory funnel, in order to separate the chloroform and lipid layer. Later, the biomass and the lipid were dried by using an oven with a temperature of $105^{\circ} \mathrm{C}$ for 2 hours. Then, the dry lipid was collected and measured with Eq. (1) [6].

$L=\frac{D L P}{D C W} \times 100 \%$ 


\subsection{Data Collection}

Stanieria HS-48 was incubated into the airlift photobioreactors (APBR) system as shown in Figure 1 below for 19 days. The specifications of the airlift photobioreactors (APBR) system for this study are listed in Table 1. Macroscopic and biomass growth data were collected every 24 hours. For the macroscopic data, the color of biomass was compared based on Faber castell standard. The Stanieria HS-48 cell was observed directly under a microscope for the microscopic data. Complementary data of environmental factors, such as temperature, $\mathrm{pH}$, and light intensity were also collected for further research.

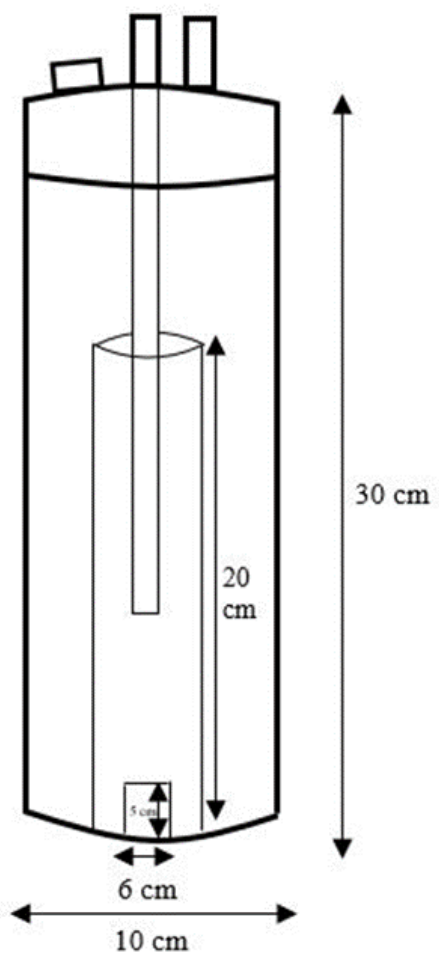

Fig. 1. Design of the airlift photobioreactors (APBR) system

Table 1

Specifications of the airlift photobioreactors (APBR) system

\begin{tabular}{ll}
\hline Description & Specifications \\
\hline Main Frame Height & $30 \mathrm{~cm}$ \\
Main Frame Diameter & $10 \mathrm{~cm}$ \\
Inner Air Pipe Length & $25 \mathrm{~cm}$ \\
Thick Lid & $5 \mathrm{~cm}$ \\
Outer Air Pipe Length & $5 \mathrm{~cm}$ \\
Lid Diameter & $10,5 \mathrm{~cm}$ \\
Out Port Pipe Length & $7 \mathrm{~cm}$ \\
Harvest Hole Dimensions (Length $\times$ Width) & $6 \times 4 \mathrm{~cm}$ \\
Flow Hole Dimension (Length $\times$ Width) & $3 \times 5 \mathrm{~cm}$ \\
Maximum Volume & $2,3 \mathrm{Liter}$ \\
\hline
\end{tabular}




\section{Results and Discussion}

\subsection{Physiology Mechanisms for Biomass Production of Stanieria HS-48}

The color of the Stanieria HS-48 starter was moss green. On day 18, the last day of observation, the color appearance of Stanieria HS-48 on NPK medium with addition of the concentration of mung bean sprout extract $2 \%$ and $4 \%$ have changed from moss green into very dark green (sap green) as shown in Figure 2. The change of colors indicates the rise of Stanieria HS-48 biomass concentration. It was affected by nitrogen additions from mung bean sprout extract that could increase chlorophyll levels and growth [7]. Also, the NPK medium with the addition of the mung bean sprout extract contains a lot of macronutrients and micronutrients for chlorophyll formation, such as nitrogen, magnesium, iron, and zinc [8].

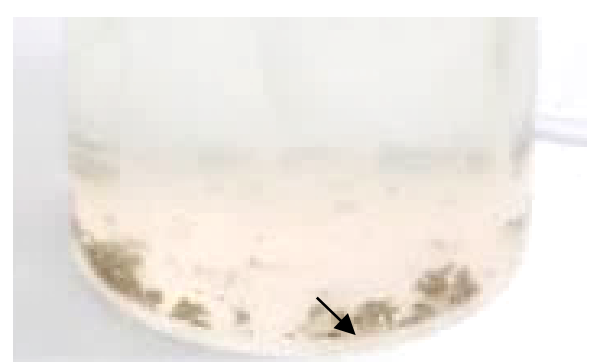

(a)

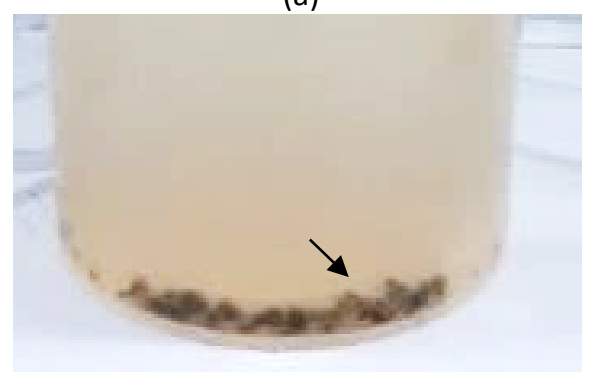

(c)

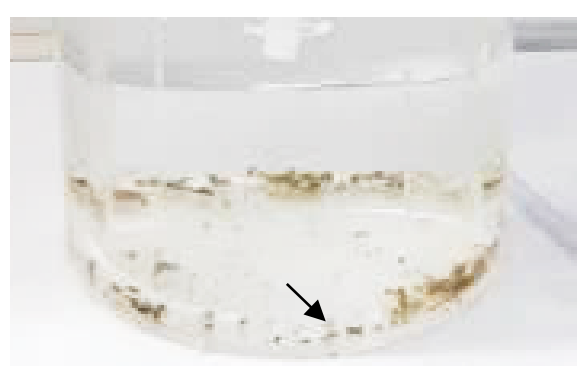

(b)

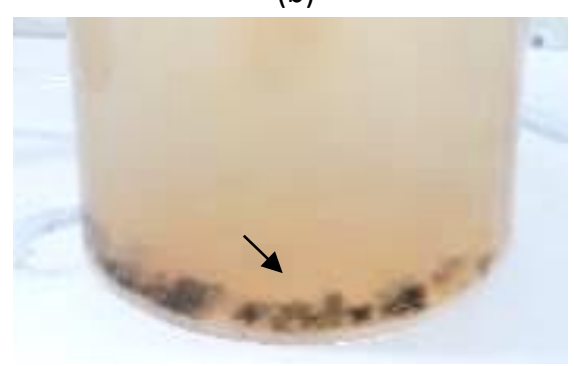

(d)

Fig. 2. Macroscopic appearance of the biomass of Stanieria HS-48 on day 18 in each medium (a) BBM (b) NPK (c) NPK $+2 \%$ of mung bean sprout extract (d) NPK $+4 \%$ of mung bean sprout extract

Stanieria cells consist of the vegetative cell and baeocyte. The microscopic appearance of Stanieria HS-48 on day 5 was Stanieria HS-48 at the exponential phase that can be seen in Figure 3. Based on the observation, Stanieria HS-48 in NPK medium with the addition of mung bean sprout extract $2 \%$ produce baeocyte with size ranged from 1.15 to $3.01 \mu \mathrm{m}$. Meanwhile, Stanieria HS-48 in NPK medium with the addition of mung bean sprout extract $4 \%$ produce baeocyte with size ranged from 1.41 to $4.42 \mu \mathrm{m}$. The cell size of Stanieria HS-48 in NPK medium with the addition of mung bean sprout extract $2 \%$ was smaller than Stanieria HS-48 in NPK medium with the addition of mung bean sprout $4 \%$. Generally, the vegetative cells have size ranged from 7.04 to $17.77 \mu \mathrm{m}$ and baeocytes have size ranged $1.6-6.88 \mu \mathrm{m}[9]$.

Based on the observation of baeocytes and vegetative cells, the number of baeocyte cells is more than vegetative cells. It was showed that vegetative cells act in multiple fissions to produce baeocyte cells. Multiple fission that occurred in vegetative cells produce $2^{5}-2^{6}$ baeocytes. Environmental factors, such as temperature can affect the condition of vegetative cells for the relative frequency of multiple fission. In temperature within the range of $20-30{ }^{\circ} \mathrm{C}$ was the optimum condition for multiple fissions [10]. Supported by environmental factors, the NPK medium with the addition of 
mung bean sprout extract $2 \%$ was optimum for Stanieria HS-48 which produces a lot of baeocyte. Mung bean sprout extract contains nutrients such as carbohydrate, protein, and fat. The polymer will be broken down into its constituent monomers which will be converted to acetyl Co-A. Acetyl Co-A product will enter the Krebs cycle and proceed to electron transport to produce Adenosine Triphosphate (ATP) for growth and division cells [11].

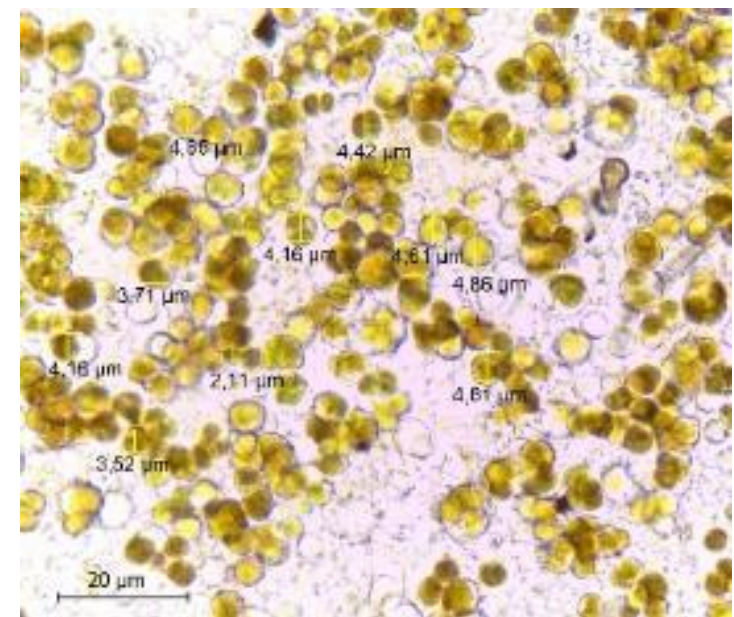

(a)

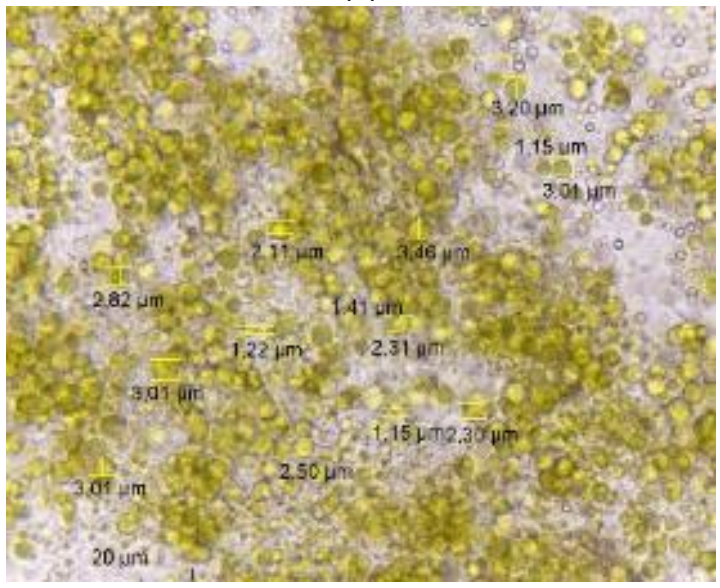

(c)

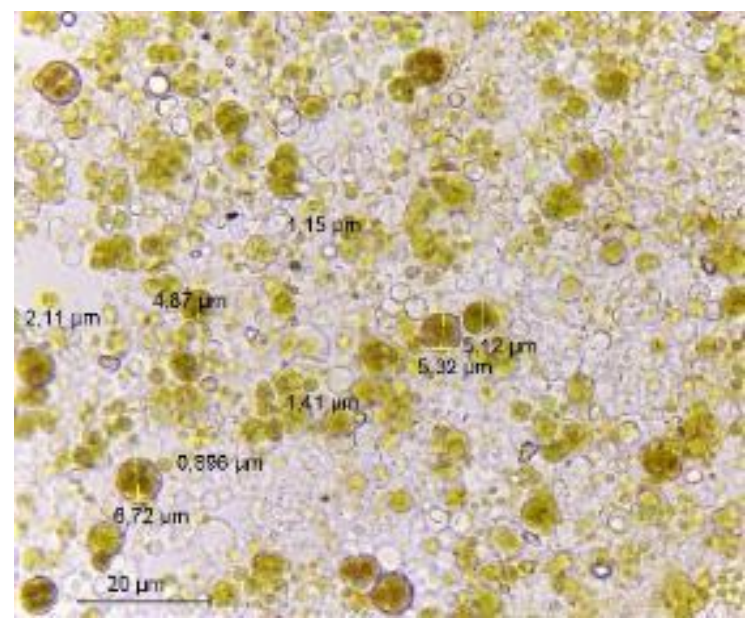

(b)

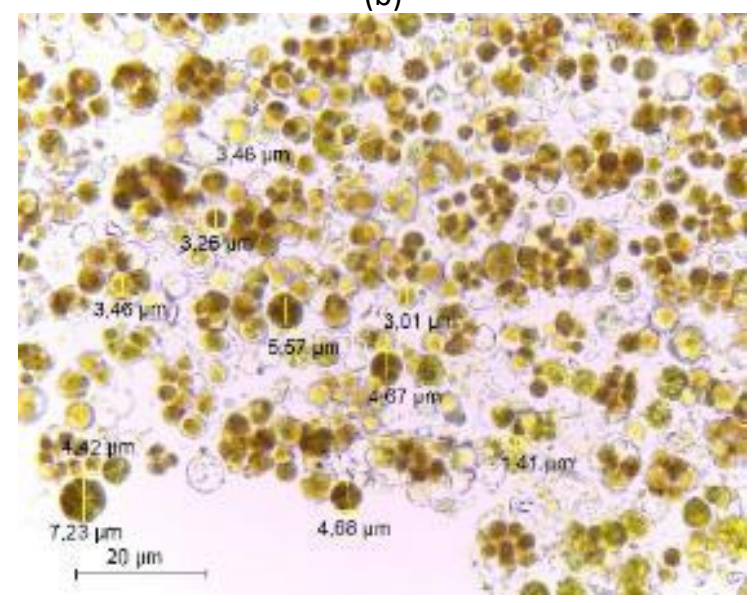

(d)

Fig. 3. Microphotograph of Stanieria HS-48 on day 5 in each medium (a) BBM (b) NPK (c) NPK + $2 \%$ of mung bean sprout extract (d) NPK $+4 \%$ of mung bean sprout extract

The addition of mung bean extract at various concentrations ( $2 \%$ and $4 \%$ ) into the NPK $350 \mathrm{ppm}$ affects the cell density of Stanieria HS-48. Based on the results, the cell density in each treatment has differences that might be affected by the concentration of the addition of mung bean sprout extract. The addition of mung bean sprout extract $2 \%$ in NPK medium has the highest total cell density at 6.1 $\times 10^{6}$ cell $/ \mathrm{mL}$ (Figure 4). Meanwhile, the highest cell density of Stanieria HS-48 in NPK medium with the addition of mung bean sprout extract $4 \%$ was $4.7 \times 10^{6}$ cell $/ \mathrm{mL}$. It was shown that the optimum concentration of mung bean sprout extract was $2 \%$ because the cell density in NPK medium with the addition of mung bean sprout extract $2 \%$ was higher than in NPK medium with the addition of mung bean sprout extract $4 \%$. Mung bean sprout extract $4 \%$ in NPK medium might have nutrients more than needed by Stanieria HS-48, so this phenomenon decreases the growth of cells. 


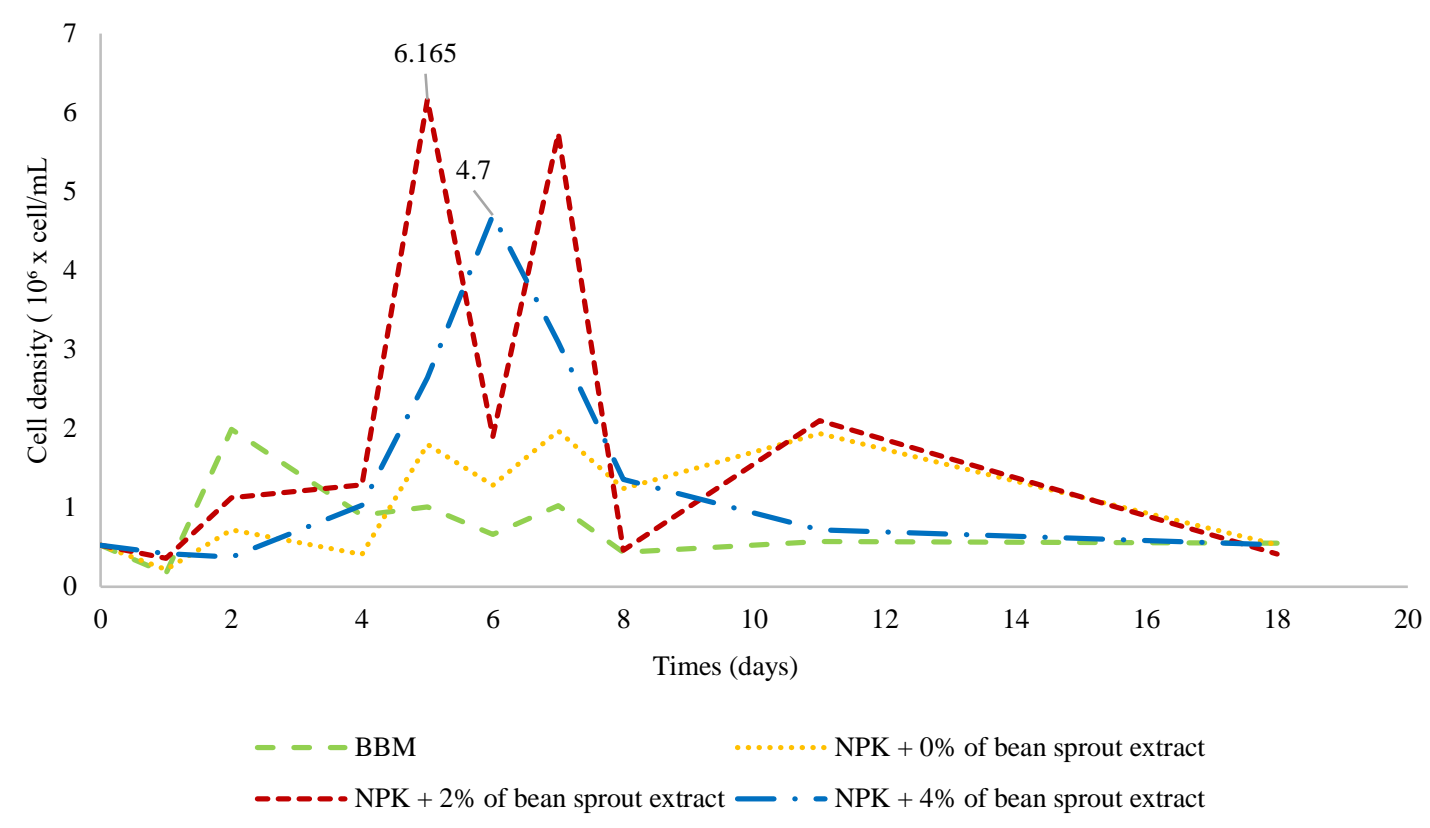

Fig. 4. The total cell density of Stanieria HS-48

\subsection{Measurement of Stanieria HS-48 Growth Rate and Doubling Time}

The growth rate can increase in cells per unit times during the exponential phase [12]. So, the growth rate can be calculated from Eq. (2).

$r=\frac{\ln \left(\frac{\mathrm{Nt}}{\mathrm{N}_{0}}\right)}{\Delta \mathrm{t}}$

Where $\mathrm{N}_{\mathrm{o}}$ is the population size at the beginning of a time interval, $\mathrm{Nt}$ is the population size at the end of the time interval, and $r$ is the rate of change. Units for $r$ is always expressed per unit time $\left(t^{-1}\right)$ [12]. Then, the growth rate $r$ can be converted to doublings per day ( $k$ ), according to the Eq. (3).

$k=r / 0.6931$

Based on all the equations, the growth rate of Stanieria HS-48 can be equated. Equations start from $t_{4}$ until $t_{5}$ and done for in all treatments. Based on the equations of the growth rate $(r)$ and doubling time $(k)$ shown in NPK medium with the addition of mung bean sprout extract $2 \%$ are higher rather than control medium summarized in Table 2.

\section{Table 2}

Growth rate and doubling time of Stanieria HS-48

\begin{tabular}{lll}
\hline Growth Medium & $r(\%)$ & $k(\%)$ \\
\hline BBM & 11 & 15.8 \\
NPK $+0 \%$ of bean sprout extract & 148 & 213.5 \\
NPK $+2 \%$ of bean sprout extract & 156 & 225 \\
NPK $+4 \%$ of bean sprout extract & 94 & 135.6 \\
\hline
\end{tabular}




\subsection{Total Lipid of Stanieria HS-48}

Stanieria HS-48 grew in NPK medium with the addition of mung bean sprout extract has higher total lipid than the control medium shown in Table 3 and Figure 5 . The result indicates that macronutrient and micronutrient in NPK medium with mung bean sprout extract support lipid accumulation, with the highest total lipid was achieved in Stanieria HS-48 in NPK medium with the addition of mung bean sprout extract $2 \%$ at $62.9 \%$. The nutrient in mung bean extract affects the photosynthesis pathway. Manganese $(\mathrm{Mn})$ is one of the micronutrients in the mung bean sprout that acts as an enzyme activator in light reaction. Besides, one of the vitamins in mung bean sprout was biotin that acts in $\mathrm{CO}_{2}$ fixation-reaction [11]. It causes the photosynthesis process to increase, which leads to more ATP for lipid production [13]. Meanwhile, the less total lipid was produced in Stanieria HS-48 in NPK medium with the addition of mung bean sprout extract $4 \%$. It might happen because there are too many nutrients in NPK medium with the addition of mung bean sprout extract $4 \%$ which may interrupt cell metabolism. One of the micronutrients that can be toxic in high concentrations is copper (Cu). Higher copper in the medium can interrupt the process of electron transport in the photosynthesis pathway [14], so it can affect the NADPH forming that is needed for $\mathrm{CO}_{2}$ reduction in the Calvin cycle [15], resulting in lipid production decrease. In order to enhance biofuel production in the areas of lipid extraction for biofuel production [16], so the addition of mung bean sprout extract in NPK medium are required.

Table 3

The dry weight and lipid percentage of Stanieria HS-48 on day 21

\begin{tabular}{llll}
\hline Growth Medium & Dry weight biomass $(g)$ & Dry weight lipid $(g)$ & Lipid \\
\hline BBM & 0.143 & 0.025 & $17.4 \%$ \\
NPK $+0 \%$ of bean sprout extract & 0.062 & 0.031 & $50.0 \%$ \\
NPK $+2 \%$ of bean sprout extract & 0.116 & 0.073 & $\mathbf{6 2 . 9 \%}$ \\
NPK $+4 \%$ of bean sprout extract & 0.243 & 0.109 & $44.8 \%$ \\
\hline
\end{tabular}

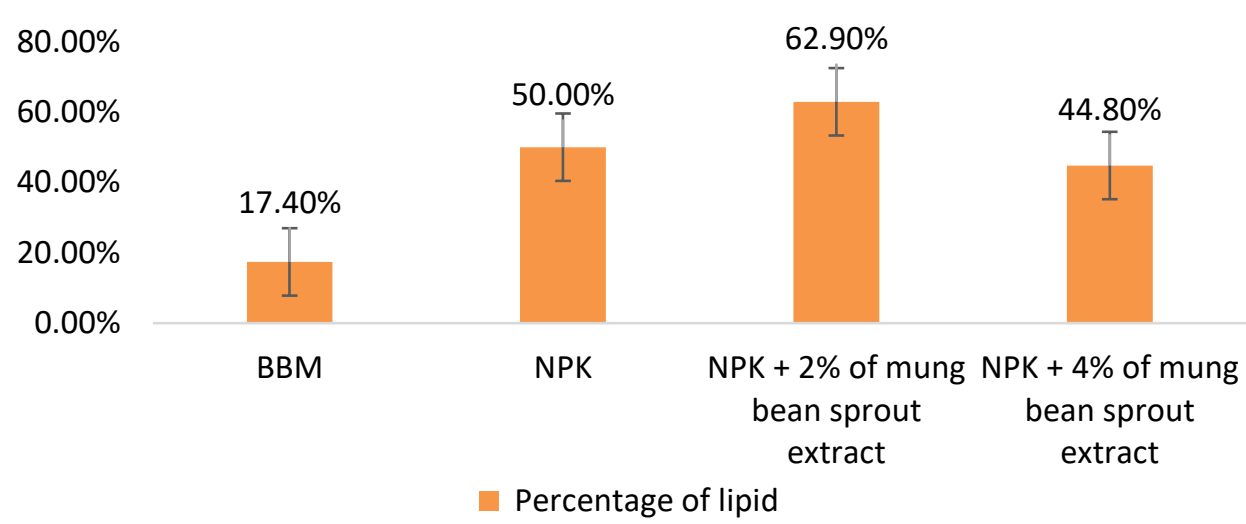

Fig. 5. The lipid percentage of Stanieria HS-48

\section{Conclusions}

Based on observation for 18 days, the NPK medium with addition of the concentration of mung bean sprout extract $2 \%$ and $4 \%$ were able to grow Stanieria HS-48. The NPK medium with the addition to the concentration of mung bean sprout extract $2 \%$ can produce biomass and lipid more than the control medium (BBM) and NPK medium with the addition to the concentration of mung bean sprout extract $4 \%$. The highest total lipid was Stanieria HS-48 in NPK medium with the addition to the 
concentration of mung bean sprout extract $2 \%$ was $62.9 \%$ with the highest cell density was $6.1 \times 10^{6}$ cell $/ \mathrm{mL}$.

\section{Acknowledgement}

This research was funded by Hibah Publikasi Terindeks Internasional (Hibah PUTI) Prosiding Tahun Anggaran 2020 to Dr. Nining Betawati Prihantini, M.Sc, grant no. NKB 987/UN2.RST/HKP.05.00/2020.

\section{References}

[1] Bellou, Stamatia, Mohammed N. Baeshen, Ahmed M. Elazzazy, Dimitra Aggeli, Fotoon Sayegh, and George Aggelis. "Microalgal lipids biochemistry and biotechnological perspectives." Biotechnology Advances 32, no. 8 (2014): 1476 1493. https://doi.org/10.1016/i.biotechadv.2014.10.003

[2] Abd El Baky, Hanaa H., Gamal S. El-Baroty, and Abderrahim Bouaid. "Lipid induction in Dunaliella salina culture aerated with various levels $\mathrm{CO}_{2}$ and its biodiesel production." J. Aquacult. Res. Dev 5 (2014): 1-6.

[3] Prihantini, Nining Betawati, Sri Handayani, Wellyzar Sjamsuridzal, and Akira Yokota. "Fatty acid characterization of indigenous cyanobacterial strains isolated from five hot springs in indonesia." In E3S Web of Conferences, vol. 67, p. 02021. EDP Sciences, 2018. https://doi.org/10.1051/e3sconf/20186702021

[4] Prihantini, Nining Betawati, Dini Damayanti, and Ratna Yuniati. "Pengaruh konsentrasi medium ekstrak tauge (MET) terhadap pertumbuhan Scenedesmus isolat Subang." Makara Journal of Science (2010). https://doi.org/10.7454/mss.v11i1.213

[5] Prihantini, Nining Betawati, Wellyzar Sjamsuridzal, and Akira Yokota. "Description of Stanieria strain of cyanobacteria isolated from hot spring in Indonesia." In AIP Conference Proceedings, vol. 1729, no. 1, p. 020066. AIP Publishing LLC, 2016. https://doi.org/10.1063/1.4946969

[6] Bligh, E. Graham, and W. Justin Dyer. "A rapid method of total lipid extraction and purification." Canadian journal of biochemistry and physiology 37, no. 8 (1959): 911-917. https://doi.org/10.1139/o59-099

[7] Rueter, John G., and Richard R. Petersen. "Micronutrient effects on cyanobacterial growth and physiology." New Zealand Journal of Marine and Freshwater Research 21, no. 3 (1987): $435-445$. https://doi.org/10.1080/00288330.1987.9516239

[8] Savage, G. P. "Nutritional value of sprouted mung beans." Nutrition Today 25, no. 3 (1990): $21-24$. https://doi.org/10.1097/00017285-199005000-00007

[9] Dewi, A. K., and Nining Betawati Prihantini. "The tolerance of isolated cyanobacteria Stanieria HS-31B and HS-48 from West Java, Indonesia in a $20^{\circ} \mathrm{C}$ environment." In AIP Conference Proceedings, vol. 2023, no. 1, p. 020172. AIP Publishing LLC, 2018.

[10] Pinevich, A. V., S. G. Averina, O. V. Gavrilova, and A. V. Migunova. "Baeocytes in the cyanobacterium Pleurocapsa sp.: Characterization of the differentiated cells produced by multiple fission." Microbiology 77, no. 1 (2008): 62-68. https://doi.org/10.1134/S0026261708010098

[11] Madigan, Michael T., John M. Martinko, and Jack Parker. Brock biology of microorganisms. Vol. 11. Upper Saddle River, NJ: Prentice hall, 1997.

[12] Andersen, Robert A., ed. Algal culturing techniques. Elsevier, 2005.

[13] Metsoviti, Maria N., George Papapolymerou, loannis T. Karapanagiotidis, and Nikolaos Katsoulas. "Comparison of growth rate and nutrient content of five microalgae species cultivated in greenhouses." Plants 8, no. 8 (2019): 279. https://doi.org/10.3390/plants8080279

[14] Lewin, Ralph A. "Physiology and biochemistry of algae." (1962).

[15] Devlin, R. M. "Plant Physiology Van Nostrand Reinhold Company." New York (1969).

[16] Aliyu, Abubakar Sadiq, Abdulkarim Ali Deba, Haruna Saidu, Ibrahim Ladan Mohammed, and Mohammed Maikudi Usman. "Biofuel development in Nigeria: Prospect and challenges." Journal of Advanced Research in Fluid Mechanics and Thermal Sciences 36, no. 1 (2017): 1-9. 